\title{
Evaluation of anti-coccidial drug sensitivity against experimental coccidiosis in broiler chicks
}

\author{
M. A. Lovelu, M. H. Talukder*, M. Z. Alam and M. A. Karim \\ Department of Parasitology, Bangladesh Agricultural University, Mymensingh-2202, Bangladesh \\ *E-mail: talukdermhasan@bau.edu.bd
}

\begin{abstract}
This study was undertaken to investigate the effect of sulphaclozine sodium and toltrazuril for the treatment of experimentally induced caecal coccidosis. Day-old chicks $(n=96)$ reared in a coccidia free condition divided into six Groups ( $A, B, C, D, E$ and $F$ ) each having 4 subgroups of 4 chicks in each. At the age of 23 days the chicks were infected with $10^{4}$ sporulated oocysts of $E$. tenella except control Group $F$ and treated for 4 consecutive days from 3 days post infection. Then treatment was given in Group $A(2 \mathrm{gm} / \mathrm{L}), B(3 \mathrm{gm} / \mathrm{L})$ with sulphaclozine sodium and in Group C (1 ml/L), D (1.5 ml/L) with toltrazuril. Group E was maintained as infected, but untreated and Group $F$ as negative control. After treatment Group A gained almost similar weight with Group $F$. A significantly higher $(P<0.05)$ weight gain was recorded in Group A and B compared with Group C and D. The infected untreated chicks passed a large number of oocysts from day 5 till the end of the experiment. Chicks receiving sulphaclozine sodium (Groups $A$ and B) had large oocysts count compared with the Groups $C$ and D treated with toltrazuril but lower than the untreated chicks. At the end of experiment the lowest oocysts count was found in Group D $\left(31.32 \times 10^{6}\right)$ and highest in Group E $\left(53.59 \times 10^{6}\right)$. Hence this study recommends to use sulphaclozine sodium and toltrazuril for chicken coccidiosis.
\end{abstract}

Keywords: Chicken coccidiosis, Eimeria tenella, Sulphaclozine sodium, Toltrazuril

\section{Introduction}

Avian coccidiosis is a parasitic disease of intestinal tract caused by single cell protozoan parasite belonging to genus Eimeria. It causes massive destruction of the epithelial cells, which leads to bloody diarrhea, reduced weight gain and temporary reduction in egg production (Dalloul and Lillehoj, 2005). Seven species have been recognized to infect poultry and each species has its own characteristics according to site of infection, immunogenicity and pathogenicity (Williams, 1998; Akhtar et al., 2012). Coccidiosis has been considered as a very harmful disease affecting growth and performance of birds in the intense poultry (Mujahid et al., 2007; Bachaya et al., 2012) and contributory factor in the pathogenesis of several diseases (Shahzad et al.,2012). A 3-years recent survey of chicken coccidiosis in Bangladesh showing the severity and persistent problem in poultry farms throughout the country inspite of using various modern anti-coccidial drugs available in the market. This retrospective study was conducted to understand the geographic and seasonal distribution of the clinical chicken coccidiosis based on the data obtained from the Epidemiology Unit of the Department of Livestock Services (DLS) and FAO, Dhaka, Bangladesh from January 2010 to December 2012 collected through passive surveillance (Talukder et al., 2015). Thus coccidiosis is probably the most harmful and wide spread infectious parasitic disease in commercial poultry farms.

In Bangladesh, a number of drugs are available for the treatment and prevention of chicken coccidiosis. Among these sulphaclozine sodium are used extensively throughout the country. In addition, ionophorous antibiotic i.e., maduramycin and lasalocid and some other drugs like amprolium, toltrazuril are also used in the field. It has been found that the efficacy of various anti-coccdial drugs varies considerably against coccidisis (Lee, 1978). Therefore, the present study was undertaken with the objective for the evaluation of the sensitivity and effect of sulphaclozine sodium and toltrazuril on the body weight against experimentally produced coccidiosis in broilers. 


\section{Materials and Methods}

\section{Bird Management}

Ninety six $(n=96)$ day-old chicks were collected from a local hatchery. After 21 days of acclimatization, the birds were divided into 6 equal Groups (A, B, C, D, E and F), each group containing 4 subgroups $(n=4)$. The chicks were reared in separate cages. Group A, B, C, D and E were coccidia induced group and Group $F$ was non-infected untreated group.

\section{Preparation of oocysts dose and infection}

For the production of fresh oocysts, each seven day aged chick $(n=6)$ got infected with $10^{4}$ sporulated oocysts. Faeces were collected from 10-11 days post infection (dpi) and were kept in $2 \%$ potassium dichromate solution, oocysts suspension was centrifuged at $500 \mathrm{rpm}$ for 5 minutes in test tubes and the supernatant was discarded. The sediment after resuspending in distilled water was centrifuged again. This process was repeated until the potassium dichromate was cleaned off. The final sediment was resuspended in distilled water and the number of oocysts per milliliter was counted by McMaster counting technique. Finally the number of oocysts as infective inocula $\left(10^{4}\right.$ sporulated oocysts) was adjusted to a volume of 0.5 to $1 \mathrm{ml}$ with water.The chicks of Group A, B, C, D \& E were infected with $10^{4}$ sporulated oocysts except the birds of Group F. The infective inoculum were introduced directly into the crop of the chick using a plastic dosing tube attached to a $1 \mathrm{ml}$ plastic syringe.

\section{Treatment schedule}

The Group A was treated with Sulphaclozine sodium @ 2 gm/L water and Group B was treated with Sulphaclozine sodium @ $3 \mathrm{gm} / \mathrm{L}$ water. The Group C and D were treated with toltrazuril @1 ml/L and @1.5 ml/L water, respectively. The Group E was maintained as infected but untreated and Group F was a control group without induction of infection and treatment.

\section{Recording of body weight and oocyts count}

Body weight was record from the day of infection $\left(D_{0}\right)$ tiil the end of experiment $\left(D_{11}\right)$. The faeces were collected everyday starting from 5 or 6 day post infection till the end of the experiment. The oocyts were counting with McMaster technique.

\section{Data Analysis:}

Group mean values of weight gain and oocysts output of the chicks were compared with student ' $t$ ' test by the help of MS Excel-2010.

\section{Results and Discussion}

This study was undertaken to compare the effect of sulphaclozine sodium and toltrazuril for the treatment of experimentally produced caecal coccidosis, Mean body weight gain and total oocysts count of each group were recorded (Table 1).

Table 1. Total body weight $(\mathrm{g})$ gain and total oocysts count of different groups

\begin{tabular}{lcccccc}
\hline Groups & Group-A & Group-B & Group-C & Group-D & Group-E & Group-F \\
\hline Body Weight gain $(\mathrm{g})$ & $71.64 \pm 27.98^{\mathrm{b}}$ & $84.27 \pm 28.66^{\mathrm{b}}$ & $78.82 \pm 26.38^{\mathrm{c}}$ & $87.27 \pm 32.1^{\mathrm{c}}$ & $40.00 \pm 7.07^{\mathrm{d}}$ & $101.82 \pm 29.19^{\mathrm{a}}$ \\
Oocyst output $\left(\times 10^{6}\right)$ & $40.41^{\mathrm{b}}$ & $34.90^{\mathrm{b}}$ & $36.51^{\mathrm{c}}$ & $31.32^{\mathrm{c}}$ & $53.59^{\mathrm{a}}$ & - \\
\hline
\end{tabular}

*Different superscripts indicate significant difference $(p<0.05)$ 
Groups mean body weight gain was varied from a minimum of 40.00 \pm 7.07 (infected untreated Group-E) to a maximum of $101.82 \pm 29.19$ (non-infected control Group-F). There was similar body weight gain in chicks of Group-A and B treated with sulphaclozine sodium @ 2gm/L and @ 3gm/L compared with the non-infected control Group-F and significantly $(P<0.05)$ higher weight gain compared to infected untreated chicks of Group-E (Fig. 1). There was slightly higher (87.27 \pm 32.17$)$ weight gain in Group-D treated with toltrazuril @1.5ml/L compared to Group-B (84.27 \pm 28.66$)$ receiving sulphaclozine sodium @ $3 \mathrm{gm} / \mathrm{L})$ only at $5 \mathrm{dpi}$, and also slightly higher weight gain $(78.82 \pm 26.38)$ in Group-C treated with toltrazuril @1 $\mathrm{ml} / \mathrm{L}$ compared to $(71.64 \pm 27.98)$ Group-A receiving sulphaclozine sodium @ $2 \mathrm{gm} / \mathrm{L}$ only at $5 \mathrm{dpi}$, but this difference was not statistically significant $(P>0.05)$. Results in weight gain and the Mean daily weight gain were shown in Table 1 and Fig. 1.

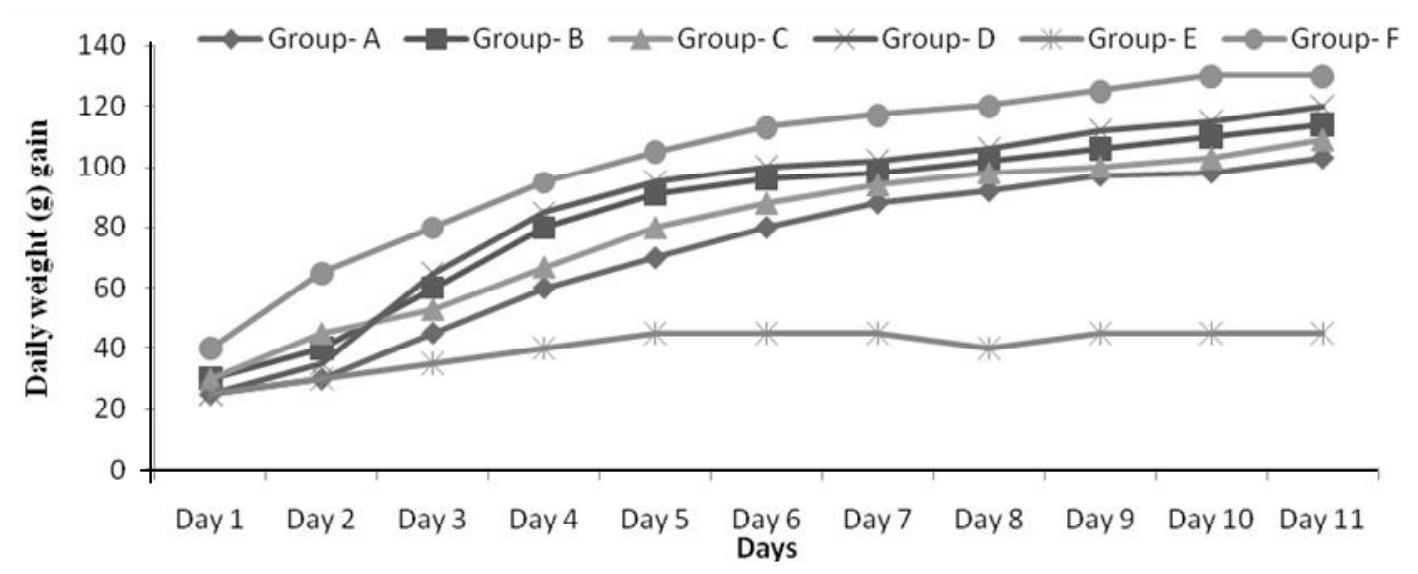

Fig. 1. Daily weight gain in different group of chicks

This depicts therapeutic efficacy of the toltrazuril. However, due to high challenge infection, the immunity remained fluctuating. The therapeutic trial in different groups from day 5 to 11 of post infection showed mark reduction of mean oocysts counts. The present findings substantiated with the findings of Grief (2000), who claimed that during evaluation studies, toltrazuril acted against all intracellular schizonts and being correlated with a higher reduction in oocyst excretion, lesion scoring and increased weight gains.

Faecal oocyst was counted from the day 5 after infection. The counting of oocysts was continued from Day 5 to Day 11.The highest oocysts count was recorded on day 5 after infection. After day 5 , the number of oocysts started to decrease gradually. The total highest count $\left(53.59 \times 10^{6}\right)$ was recorded in infected untreated Group $E$ and the total lowest count $\left(31.32 \times 10^{6}\right)$ was recorded in Group D treated with toltrazuril @1.5ml/L. The details of the daily oocysts output were shown in the Fig. 2 and the total oocysts output is shown in the Table 1.

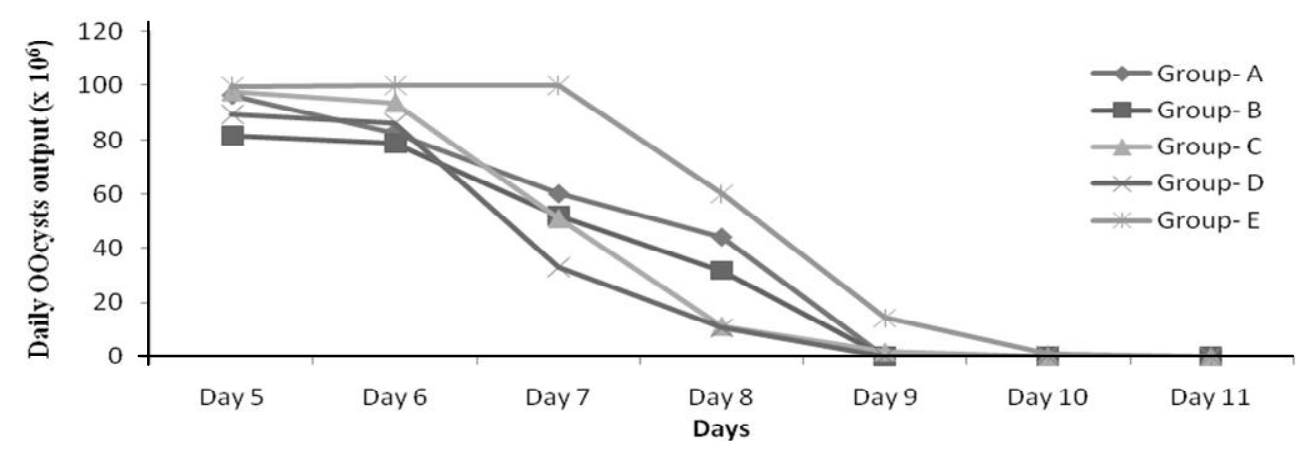

Fig. 2. Daily oocysts production in different group of chicks 
In this study, $10^{4}$ oocysts of Eimeria tenella once directly introduced into the crop of chicks normally produce a moderate to severe infection with a very low rate of mortality as reported by Karim (1988). Faecal oocysts count and body weight gain were used as the criteria for the detection of infection and severity of infection. However, faecal oocysts count may not always correspond with the weight depression and oocysts may be produced without apparent effect on weight gain (Karim, 1988).

Since the non-infected control chicks had a steady and uninterrupted gain in weight and it can be presumed that the effect on body weight gain was due to experimental infection. In addition, since the premises, waterer, feeder, brooder etc. were disinfected with ammonia that kills Eimeria oocysts (Xie et al., 1983), the possibility of any additional infection can be excluded for the depression. The maximum mean weight gained $101.82 \pm 29.19$ seen in group of non-infected healthy chicks (Group-F) and the minimum mean weight $40.00 \pm 7.07$ achieved by the infected untreated chickens (Group-E) support this.

This study could be compared with Dhillon et al.(2004), who tested the efficacy of toltrazuril against 6 different levels of Eimeria tenella infection in 2-week- old chicks and found that the treatment resulted to lower mortality and reduced oocyst production. Moreover, therapy resulted to complete elimination of the clinical signs at lower levels of infection rate which were 100 and $0 \%$ respectively.

The chicks treated with sulphaclozine sodium monohydrate has the lowest oocyst output, but the number of oocysts produced was not negligible. That indicates a degree of resistance.Complete cessation of oocyst production 3 days post-treatment with sulphaclozine sodium @ 2 gm/litre and high degree of efficacy of toltrazuril @ 1.5ml/litre were found by Padmavati et al. (1995).

Siddiki et al. (2000) found that chicks treated with sulphaclozine sodium monohydrate @1 gm/litre voided a large number of oocysts and @ 2.5gm/litre of drinking water voided a less number of oocysts. In this experiment relatively large oocysts counts in chicks treated with sulphaclozine sodium @2gm/litre than sulphaclozine sodium @ $3 \mathrm{gm} /$ litre for 4 consequtive days further substantiated the low degree of resistance of Eimeria tenella against sulphonamide.

Two birds of Group-E were died at $6 \mathrm{dpi}$. On post-mortem examination the caeca were highly swollen with full of clotted blood and showed large number of hemorrhagic and necrotic spots on the mucosal surface. A large number of oocysts and other developmental stages were found in the mucosal scrapings. Post treatment (anti-coccidial drugs) findings of caeca; swollen with full of clotted blood, large number of hemorrhagic and necrotic spots on the mucosal surface were cured that found at post-mortem examination of caeca after 10 days.

\section{Conclusion}

Though this experiment revealed that both the tested drugs showed higher body weight gain and decreased oocysts output after treatment, toltrazuril as provided better performance interms of body weight gain and oocysts count. Therefore, this study recommends the use of sulphaclozine sodium and toltrazuril for chicken coccidiosis.

\section{References}

Akhtar, M., Anwar, M.I., Iqbal, Z., Muhammad, F., Awais, M.M., Haq, A.U. and Sawicka, E.H. 2012. Immunological evaluation of two local isolates of Eimeria tenella gametocytes against coccidiosis in poultry. Pakistan Veterinary Journal, 32: 77-80.

Bachaya, H.A., Raza, M.A., Khan, M.N., Iqbal, Z., Abbas, R.Z., Murtaza, S. and Badar, N. 2012. Predominance and detection of different Eimeria species causing coccidiosis in layer chickens. Journal of Animal and Plant Science, 22: 597-600.

Dalloul, R.A. and Lillehoj, H.S. 2005. Recent advances in immunomodulation and vaccination strategies against coccidiosis. Avian Diseases, 49: 1-8.

Dhillon, N.K., Jasmer, S., Bal, M.S. and Ashuma, T. 2004. Efficacy of toltrazuril against different levels of Eimeria tenella infection in chicken. Journal of Research, Punjab Agricultural University, 41(1): 150-155.

Grief, G. 2000. Immunity to coccidiosis after treatment with toltrazuril. Parasitology Research, 86 (10): 787-790. 


\section{Lovelu et al.}

Karim, M.J. 1988. Intra specific variations in avian coccidia of British and Bangladeshi origin. Ph. D. Thesis submitted to the University of Liverpool, England, August 1988. p. 34.

Lee, M. 1978. The effect of Sulphonamide on the course of experimental avian coccidiosis. Library of Congress Catalog Card No.61.9214. $3^{\text {rd }}$ printing. USA, pp. 216.

Mujahid, A.Y. Askiba and Toyornizu, M. 2007. Acute heat stress induces oxidative stress and decreases adaptation in young White Leghorn cockerels by down regulation of avian uncoupling protein. Poultry Science, 86: 364-371.

Padmavati, P., Ramesh, A.J. and Gangadhar Rao, Y.V.B. 1995. Studies on the therapeutic efficacy of Esb $3^{\circledR}$ against experimental mixed coccidial infection in chickens, Indian Veterinary Journal 72: 690-693.

Panda, D.N., Mishra, A., Mishra, S.C. and Rao, A.G. 1999. Efficacy of Esb3 ${ }^{\circledR}$ in the treatment of experimental Eimeria tenella infection in broiler chicks, Indian Veterinary Journal 76: 199-201.

Siddiki, A.M.A.M.Z., Karim, M.J., Islam, M.K. and Alam, M.Z. 2000. Sulphonamide resistance in field isolates of chicken coccidia in Bangladesh. The Bangladesh Veterinarian, 17(1) pp. 11-15.

Shahzad, A, Mahrnood, M.S., Hussain, I., Siddique, F. and Abbas, R.Z. 2012. Prevalence of salmonella species in hen eggs and egg storing-trays collected from poultry farms and marketing outlets of Faisalabad, Pakistan. Pakistan Journal of Agricultural Sciences, 49: 565-568.

Talukder, M.H., Islam, S.S., Rahman A.K.M.A., Bhuiyan, M.K., Debnath, A.K. 2015. A Retrospective Analysis of the Clinical Chicken Coccidiosis for Three Years in Bangladesh (Abstract P0184). Proceedings of the World Veterinary Poultry Association at Cape Town International Conference Centre, Cape Town, South Africa September 7-11 2015.

Williams, R.B. 1998. Epidemiological aspects of the use of live anticoccidial vaccines for chickens. International Journal of Parasitology, 28: 1089-1098.

Xie, M.Q., Lu, Y.M. and Wen, L.N. 1983. Coccidiostatic and coccidiocidal test on coccidial oocysts of chickens. Chinese Journal of Veterinary Medicine, 9(10): 2- 5. 